\title{
A new species of Austrodecus Hodgson, 1907 (Pycnogonida, Austrodecidae) from the Chilean fjords
}

\author{
Vid Švara ${ }^{1 *}$ and Roland R. Melzer ${ }^{2,3}$
}

\begin{abstract}
A new species of the "glaciale" group of Austrodecus Hodgson, 1907, Austrodecus nausinoos sp. n., is described from specimens collected by "Huinay Fjordos" expeditions to the southern Chilean fjords in 2005, 2011 and 2013. Specific to the new species is the combination of the following morphological characters: six-articled ovigers, auxiliary claws, two spines on the first coxa of leg 1, and a spur at the tip of the long abdomen. In addition to the species description we give an update of Child's (1995) key to the glaciale group of Austrodecus including the new species.
\end{abstract}

Keywords: Southern Chilean fjords, Postglacial colonization, Pycnogonida, Austrodecus

\section{Background}

For more than 10 years the "Huinay Fjordos Expeditions", organized by Vreni Häussermann and Günther Försterra of the Huinay Scientific Field Station (Huinay, Chile) have established inventories of fauna and biocoenoses of the southern Chilean fjords [8], a region that went through several cycles of glaciation-driven phases of extinction of benthic communities and subsequent recolonization during warmer periods. In this respect, the Pycnogonida with their holobenthic life cycle as "brooders", and hence limited dispersal capacity, proved very interesting in phylogeographic analyses. Those revealed both "cryptic" species that still have to be studied in more detail $[7,11,12]$, and "non-cryptic" species that show specific morphological characters, e.g. Pallenopsis yepayekae Weis 2014 [12]. In this paper we describe a new species of Austrodecus Hodgson, 1907 (Austrodecidae), collected during the Huinay fjordos expeditions, that is morphologically and geographically distinct from other species in this genus.

The pycnogonid genus Austrodecus currently consists of 42 species [1], of which over $90 \%$ are found in the

\footnotetext{
*Correspondence: vid.svara@gmail.com

1 Department of Biology, Biotechnical Faculty, University of Ljubljana,

Večna Pot 111, 1000 Ljubljana, Slovenia

Full list of author information is available at the end of the article
}

southern hemisphere. Most of the species were described in previous century in contrast to only three additions to the genus in the past 15 years, viz., Austrodecus (Tubidecus) oferrecans Bamber, 2000 Austrodecus childi Arango, 2003 and Austrodecus bamberi Wang, Huang, Lin \& Zheng, 2013. The first overview of Austrodecidae was provided by Stock [10], which included a genus division into four groups based on the presence or absence of auxiliary claws and the structure of the ovigers. The glaciale section of the division consisted of the majority of the species distributed around the Antarctic, including a few species from the seas around Southern South America. Almost half a century after Stocks overview another comprehensive work was published [2], however the glaciale group was not included. Finally, Child [3] published a monograph about representatives of Austodecidae found in the Antarctic. This work also includes species from subantarctic seas, such as A. curtipes Stock, 1957, A. calcaricauda Stock, 1957 and A. glabrum Stock, 1957 and a taxonomic key, based on Stock's group division. Beside that Hedgpeth [9] identified Austrodecus curtipes from material collected by the Lund University Chile expedition in the Strait of Magellan. The latter species is the only one that has been found in close proximity to the South American coast in the past. 
During "Huinay Fjordos" expeditions, Austrodecus specimens were collected by one of the authors in 2005, 2011 and 2013. The first two specimens (Comau fiord, 2005), following Hedgpeth [9], were assigned to A. curtipes, but some differences to this species were observed. Therefore more material was collected in 2011 (1 specimen, again from Comau fjord) and in 2013 (3 specimens, from Guarello Island) indicating that the observed differences were constant features, not within-trait variability of any of the other known representatives. We can thus confirm a new species of pycnogonid which is described below.

\section{Methods}

Specimens from which the data is obtained were collected in two areas along the coast of Southern Chile, i.e. Comau fjord (Lillihuapi Isl., Punta Huinay and Punta Grueza), and from Isla Guarello (Muro Roberto, Cono Guarello) (Fig. 1). They were all sorted from samples taken during SCUBA dives of either colonial hydrozoans or aufwuchs of polychaete colonies, Chaetopterus sp. The samples include 6 individuals, of these 2 male, 3 female and one juvenile.

All the specimens were preserved in $96 \% \mathrm{EtOH}$. Specimens were mounted on microscope slides, using $86 \%$ glycerol, and studied under the microscope Leica DM5000 B equipped with a Jenoptik ProgRes SpeedXT Core 5 digital camera. Photos and measurements were made in the ProgRes CapturePro v2.8.0 software. In addition, a photo macroscope (Wild M400) equipped with a digital camera (Nikon D700) was used to produce several shots focused at different levels along the $\mathrm{z}$-axis from the dorsal ventral and lateral sides. Extended depth of field photos were generated with Helicon Focus (http://www. heliconsoft.com/). Digital drawings (digital inking) were made in Adobe Illustrator CS3, using photographs of the appendages with a Wacom digital drawing board and digital pen [4-6].

\section{Systematics}

Class Pycnogonida Latreille, 1810

Order Pantopoda Gerstäcker, 1863

Suborder Stiripasterida Fry, 1978

Family Austrodecidae Stock, 1954

Genus Austrodecus Hodgson, 1907

Austrodecus nausinoos sp. n.

Zoobank: http://zoobank.org/98CE275A-1876-4B10-8B98F3E25D63289F (Figs. 2, 3).

Material examined ZSMA20051958, male, Chile, Lagos, Comau fjord, Lilihuapi Isl., $42,1500^{\circ} \mathrm{S}, 72,5833^{\circ} \mathrm{W}$, 24.2.2005, 5-36 m deep (holotype); ZSMA20051959, male, Chile, Lagos, Comau fjord, Punta Gruesa, $42,4000^{\circ} \mathrm{S}, 72,4167^{\circ} \mathrm{W}, 22.2 .2005,20-30 \mathrm{~m}$ deep (paratype); ZSMA20111176, female, Chile, Lagos, Comau fjord, Punta Huinay, $42,3667^{\circ} \mathrm{S}, 72,4167^{\circ} \mathrm{W}, 20-35 \mathrm{~m}$ deep (paratype); ZSMA20119990, female, Chile, Magallanes, Madre de Dios Archipelago, Isla Guarello, Muro Roberto, 50,3381 ${ }^{\circ} \mathrm{S}, 75,3815^{\circ} \mathrm{W}, 17.4 .2013,20 \mathrm{~m}$ deep (paratype); ZSMA20119992, juvenile, Chile, Magallanes, Madre de Dios Archipelago, Isla Guarello, Cono Guarello, 50,3594 ${ }^{\circ} \mathrm{S}, 75,3385^{\circ} \mathrm{W}, 19.4 .2013,20 \mathrm{~m}$ deep (paratype); ZSMA20119994, female, Chile, Magallanes, Madre de Dios Archipelago, Isla Guarello, Cono Guarello, $50,3594^{\circ} \mathrm{S}, 75,3385^{\circ} \mathrm{W}, 19.4 .2013,20 \mathrm{~m}$ deep (paratype). The type series is deposited in Bavarian State Collection of Zoology, at department Arthropoda varia.

Type locality Lilihuapi Isl., Chile, $42,1500^{\circ} \mathrm{S}$, 72,5833ํㅏ, 5-36 $\mathrm{m}$ deep.

Distribution Southern coast of Chile, from $42,15^{\circ} \mathrm{S}$ to $50,20^{\circ} \mathrm{S}$ latitude.

Diagnosis Trunk (Fig. 2a, b) with four dorsomedian tall tubercles. All of the first coxae with a pair of dorsodistal tubercles in the formula 2:2:2:2. Cement gland (Fig. 3g) in the males is clearly visible, dome shaped, and situated at about the midpoint of the ventral side of each femur. Abdomen (Fig. 3b) has a dorsal spur at the distal end.

Description Size is small for the genus $(915 \mu \mathrm{m}$ in length, $450 \mu \mathrm{m}$ in width); leg span measured from "dactylus tip to dactylus tip" is approximately $4 \mathrm{~mm}$. Trunk (Fig. 1a, b) slender in males, stout and rounded in females, completely segmented. Dorsal segmented lines slightly raised, with 4 long dorsomedian tubercles. Lateral processes separated by at least half of their diameter. Ocular tubercle (Fig. 3a) situated on the anterior third of cephalosoma, short, pointed at the distal part (diameter $80 \mu \mathrm{m}$ ), stout at the base (diameter $165 \mu \mathrm{m}$ ). Eyes (Fig. 3a) located on the distal part of ocular tubercle with weak or no pigmentation. Proboscis (Fig. 2b) typical for the genus, slender, relatively short $(500 \mu \mathrm{m})$-note that the tip is broken off in the holotype that was used for the drawing; with about 35 annulations and a wider base. It is a similar size to the trunk, distal part curved ventrally. Abdomen (Fig. 3b) slightly erect, extending over third coxa of fourth pair of legs, and carrying 4 setae and a dorsal spur at the tip. It is covered with irregularly arranged papillae.

Palps (Fig. 2a, b) six-articled, $890 \mu \mathrm{m}$ in length. First article broad, without spines or setae. Second article longest, with 2 short setae and a spine. Articulation lines 


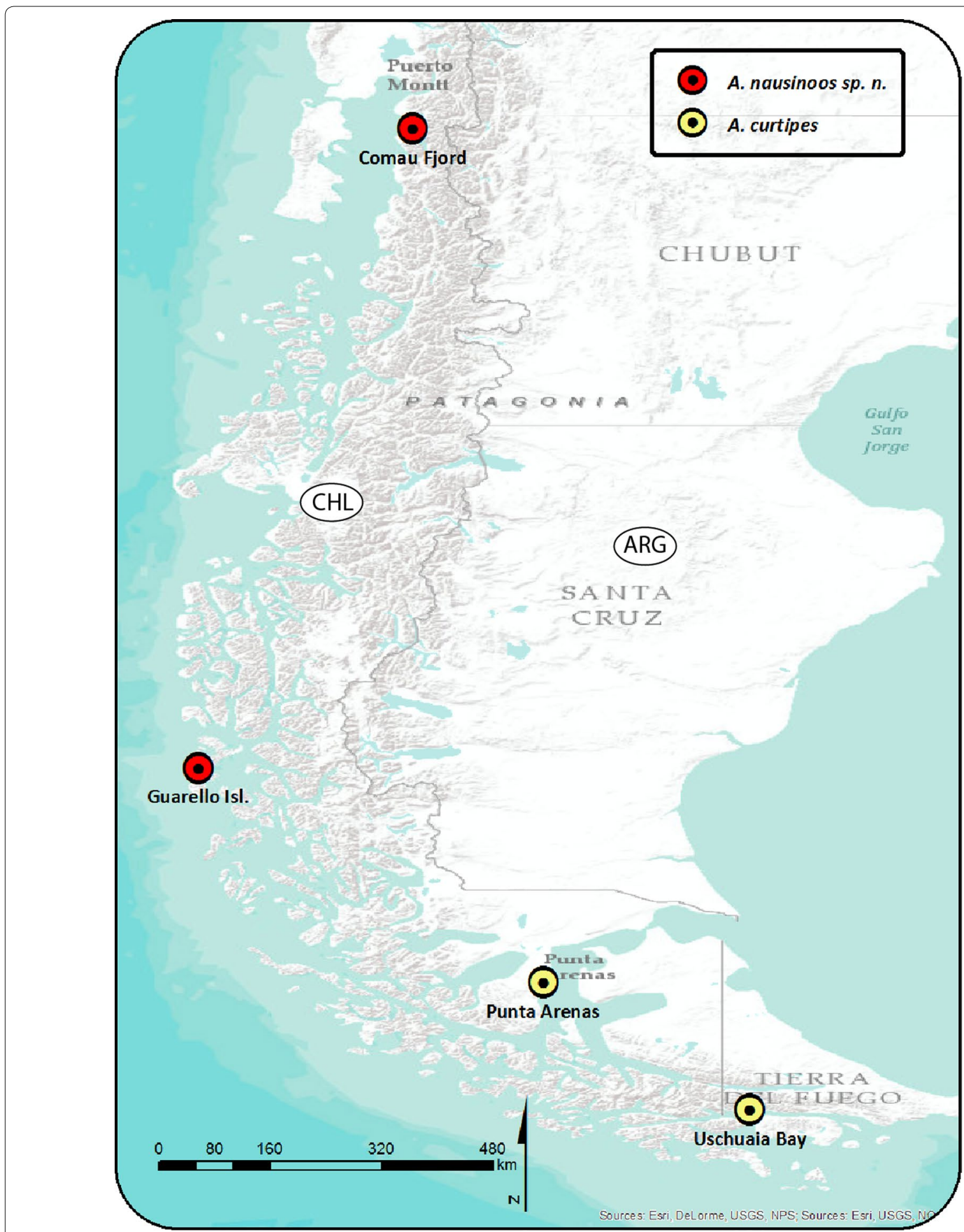

Fig. 1 Distribution map of A. nausinoos sp. n. and geographically closest records of A. curtipes

between second, third, and fourth article indistinct. Third article short, without spines and setae. Fourth article half the length of second article, bearing four spines on the inner side and three setae on the outer side. Distal two articles short. Terminal article synaxial to penultimate 

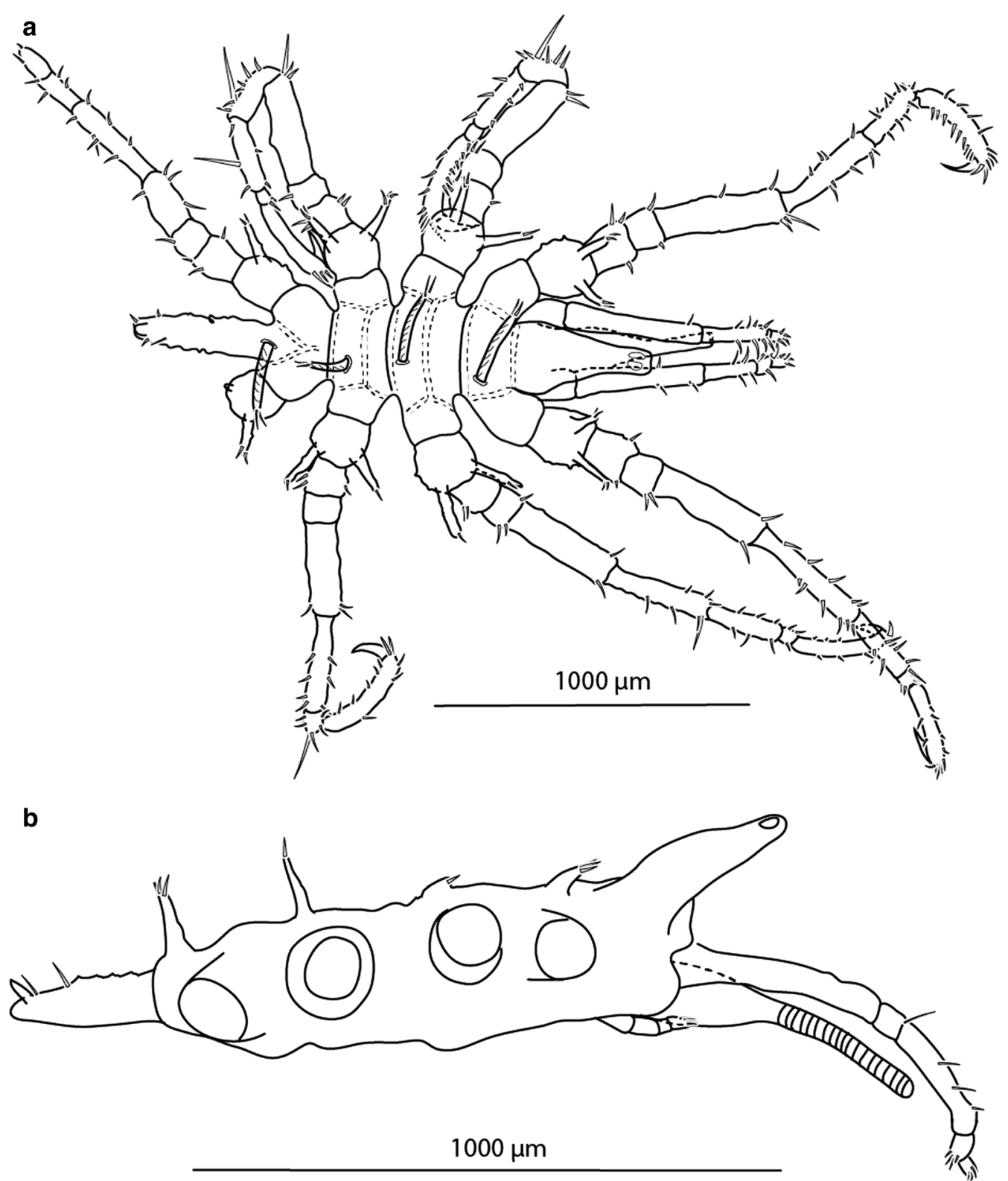

Fig. 2 Austrodecus nausinoos sp. n., ZSMA20051958, male, holotype: a habitus, dorsal view, b lateral view of the trunk with the abdomen, proboscis, palp and oviger

article, both armed with 8 and 10 ventral and distal setae the size of their article's diameter.

Ovigers (Fig. 3c, d) small, $230 \mu \mathrm{m}$ in length, 6 articulated. First to third articles without setae, fourth and fifth articles carrying a single seta each. Last article with 7 terminal and subterminal setae, slightly rounded in male, straight in female. Juvenile without developed ovigers.

Legs slender (Fig. 3e) with tiny papillae. Coxa (Fig. 3f) 1 of each leg with 2 equally long slender tubercles. Second and third coxa shorter, with 2 and 3 setae respectively, without spines. Femur (Fig. 3g) the longest article, with 7 setae. Cement gland (Fig. $3 g$ ) in male is clearly seen, dome shaped, situated at about midpoint of the ventral side of each femur. Female without cement glands. Tibia 1 longer than tibia 2, with 6 and 1 setae. Tarsus with 1 seta, short. Propodus (Fig. 3h) moderately curved, carrying 9 setae. Main claw (Fig. 3h) strong, $140 \mu \mathrm{m}$ long, two auxiliary claws at the outer side, reaching half of the length of the main claw $(70 \mu \mathrm{m})$. 
a

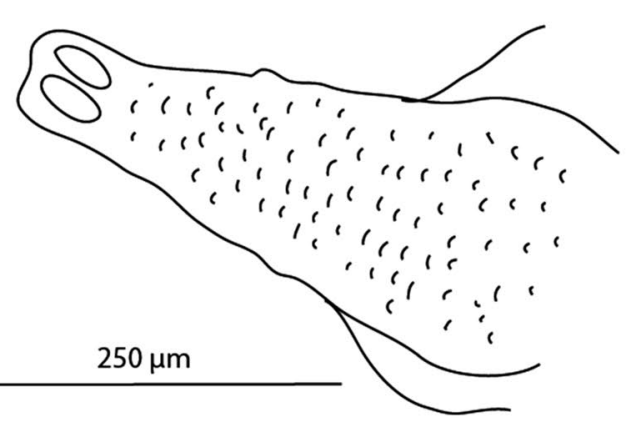

c

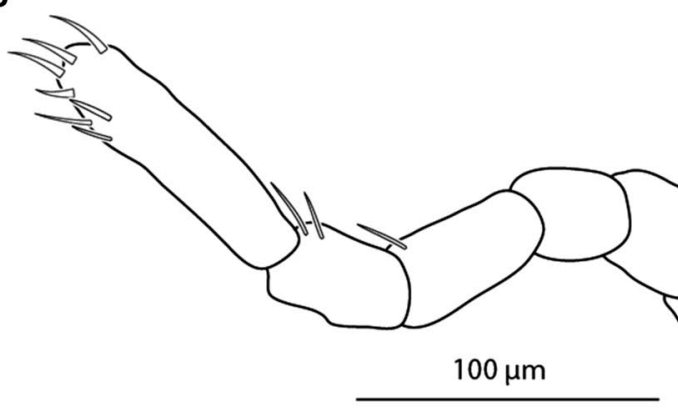

e

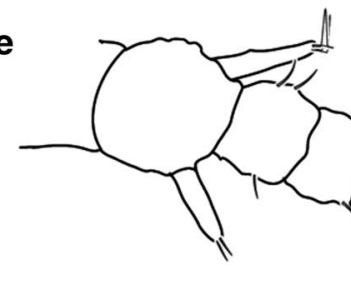

$300 \mu \mathrm{m}$

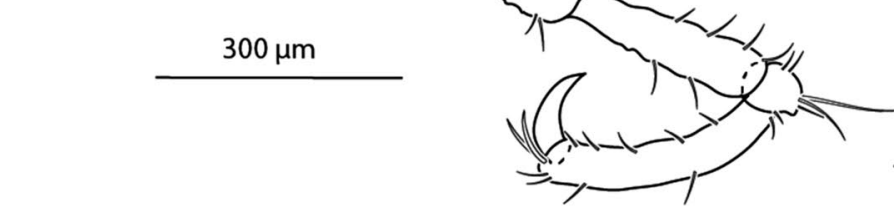

g)

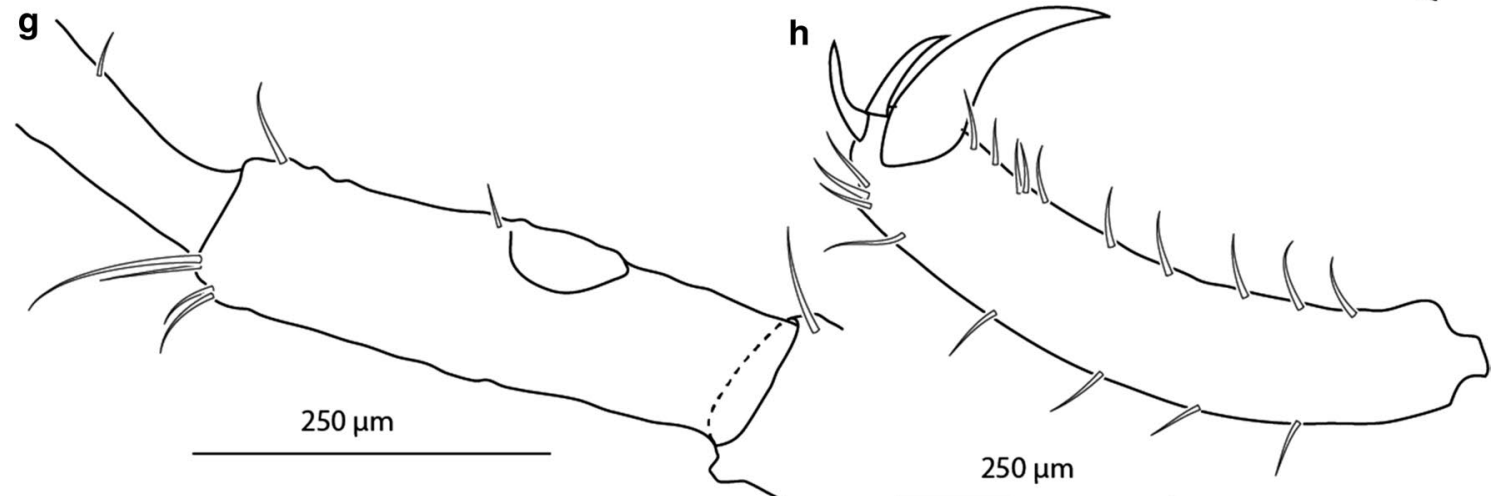

b

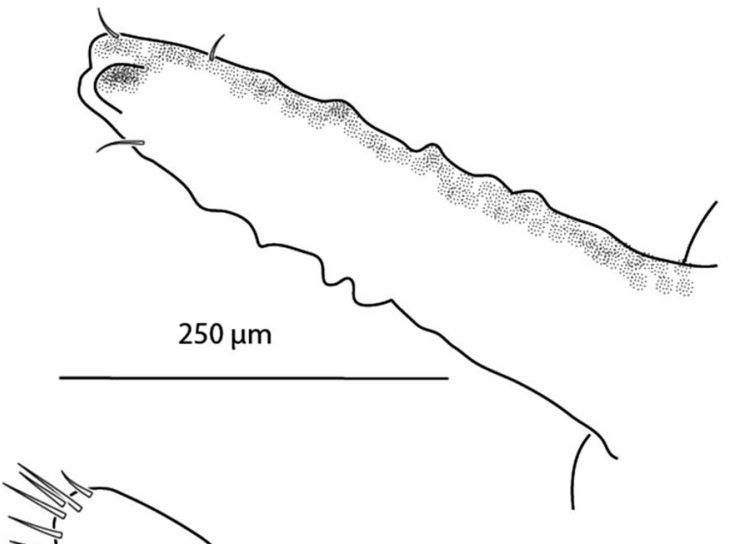

d

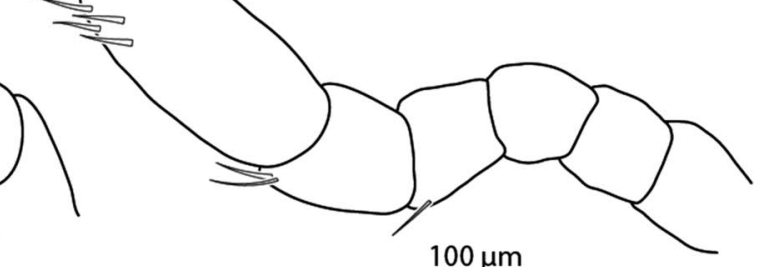

$100 \mu \mathrm{m}$

Fig. 3 Austrodecus nausinoos sp. n., ZSMA20051958, male, holotype: a ocular tubercle with eyes and papillae, b abdomen, c oviger male, d oviger female (ZSMA20111176), e leg 3 dorsal view, $\mathbf{f}$ leg 1 coxae, $\mathbf{g}$ leg 1 femur with cement gland, h leg 1 claw, auxiliary claws and propodus 


\section{Measurements [ $\mu \mathrm{m}]$}

Trunk length (from cheliphore insertion to tip of 4th lateral processes), 915 (885-1130); width across 2nd lateral processes 450 (448-780); processus gap 1:3 (1:(2.2-3.4)); proboscis length 500 (500-1005); ocular tubercle distal width 81 (71-83), proximal width 165 (165-183); abdomen length 544 (544-763).

Length of a palp 890; length of an oviger 230 (215320 ); third leg length: coxa 1,152 , coxa 2,104 , coxa 3,75 , femur, 267 , tibia 1,205 , tibia 2,182 , tarsus, 58 , propodus, 260, claw, 140, auxiliary claw 70 .

\section{Etymology}

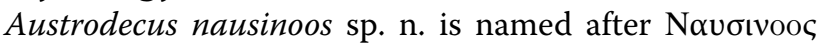
(Nausinoos), son of Calypso and Odysseus. The ancient Greek name denominates an expert of ships or seafaring ("smart mariner"), and thus fits well to a species of the "glaciale group" that colonized waters far in the north from its roots in Antarctic waters.

Remarks This species belongs to the $A$. glaciale section sensu lato Stock [10] which is characterized by 6 -articled ovigers and the presence of auxiliary claws. The species closely resembles $A$. curtipes with a similar body shape and taxonomic characters, but differs significantly in the number of spines on the first coxa of leg 1 (2 spines in A. nausinoos sp. n.; 1 spine in A. curtipes) and the spur on the tip of abdomen. Moreover, it can be distinguished from A. longispinum by its smaller body size, absence of spines on the second and third coxa and a longer abdomen.

If we consider the taxonomic key by Child [3], an unknown specimen that would eventually belong to newly described species, could be misidentified as Austrodecus longispinum Stock, 1957. Therefore we give an update of Child's key including additional steps separating A. nausinoos sp. n. from its close relatives (see below).

Our records of $A$. nausinoos sp. n. from Lilihuapi Isl. and Comau fiord are by far the northern most records of members of the "glaciale group" in Southern South America (Fig. 1). They are located at similar latitudes as the records of the Prince Edward Islands and South Island of New Zealand. In his 1957 analysis, Stock already found indications that the "glaciale group" might have its origin in the Antarctic and Subantarctic, and secondarily colonized more northern latitudes. In recent years growing evidence indicates that the Chilean fjords are in interglacial phases and after the last ice age were recolonized not only from the North, but also from multiple antarctic and subantarctic glacial refugia (for Pycnogonida see, e.g., [7, 12]). A. nausinoos sp. n. might be another example of this pattern. Hence, a phylogeographic analysis of "glaciale group" of Austrodecus could help a lot to understand pycnogonid speciation in the Southern Ocean and adjacent marine regions.

\section{The taxonomic key for Austrodecus glaciale group including A. nausinoos sp. n. modified after Child [3]}

\section{1a) First coxae with tubercles arranged from $\quad 2$ anterior to posterior coxae as $1,2,2,1$ \\ b) $\quad$ First coxae with tubercles arranged in other $\mathbf{6}$ sequences from anterior to posterior \\ 2a) Abdomen without any form of distal $\quad 3$ tubercle; palp terminal segments articulated synaxially, not coalesced or fused; auxiliary claws at least 1/3 length of main claw}

b) Abdomen with small distal tubercle; palp terminal segments coalesced, mittenshaped; auxiliary claws very short, less than $1 / 3$ length of the main claw

Trunk with low bumps only as dorsomedian tubercles; ocular tubercle short; femoral cement gland other than a low broad cone

b) Trunk with tall slender median tubercles; ocular tubercle long and slender; cement gland a low broad cone

Femora longest leg segments, cement gland orifice a slender curve-sided cone or a low bump; oviger terminal segment length equal to or longer than fourth segment

First tibiae longest leg segments, cement gland orfice a slender straight-sided cone; oviger terminal segment longer than fourth

5a) Cement gland orifice a very slender concave-sided cone; oviger terminal segment length equal to fourth

b) Cement gland orifice a low rounded bump; oviger terminal segment longer than fourth

6a) Coxae 1, coxae 2 with single tubercle each

b) Coxae 1, coxae 2 with different tubercle arrangement

7a) Trunk with conspicuous dorsomedian tubercles, lateral processes closely crowded; abdomen with distal tubercle

b) Trunk with few papillae, without dorsomedian tubercles, lateral processes separated by their diameters or more; abdomen without distal tubercle

8a) Dorsomedian trunk and abdominal tubercles taller than basal diameter; ocular tubercle very long, with eyes; proboscis very long, equal to trunk length; palp two terminal segments hardly longer than their diameters
A. cestum Child

\section{4}

A. simulans Stock 5

\section{A. profundum Stock}

A. pushkini Child

A. fagei Stock 7 9

8

A. varum Child

A. calcaricauda Stock 
b) Dorsomedian trunk and abdominal tubercles shorter than broad basal diameter; ocular tubercle short, blind; proboscis short, less than trunk length; palp two terminal segments twice as long as their diameters

9a) First coxae of first legs with single tubercle, other first coxae with two distinct tubercles

b) First coxae with different tubercle arrangement

10a) Dorsomedian trunk tubercles broad based, tapering to point; lateral processes closely crowded to well separated; ocular tubercle short or long

b) Dorsomedian trunk tubercles tall, pointed parallel sided over most of length; lateral processes robust, closely crowded; ocular tubercle moderately short, with bulbous base, flat at tip in dorsal view; femoral cement gland a low proximal bulge

11a) Ocular tubercle short, blunt, with little taper; lateral processes crowded, partly touching; propodus with many sole spines; cement gland orifice a very small cone with lateral pore

b) Ocular tubercle moderate to usually long,well tapered; lateral processes well separated, never touching; propodus with very few sole spines; cement gland a broad cone as long or longer than femur diameter, pore distal

12a) All first coxae with two dorsodistal tubercles

b) First coxae with different tubercle arrangement

13) Trunk with 4 slender dorsomedian tubercles; ocular tubercle moderately short, very broad based; cement gland a low proximal cone half femoral diameter

b) Trunk without tubercles, but with dorsomedian papillae; ocular tubercle long, slender, not excessively broad based; cement gland a tall cone equal to femur diameter

14a) Ocular tubercle moderately short; rugosities on coxae two; third coxae of all legs with a with a single dorsodistal tubercle; abdomen without dorsal spur at distal end

b) Ocular tubercle moderately short to usually long; no rugosities on coxa two; third coxae of all legs without dorsodistal tubercle; abdomen with a dorsal spur at the distal end

\section{A. sinuatum \\ Stock}

10

12

11

A. curtipes Stock

A. serratum Child

A. glaciale

Hodgson

13

A. macrum Child

14

A. glabrum Stock

A. longispinum
Stock

A. nausinoos

sp. n.

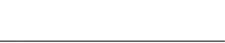

\section{Author details}

${ }^{1}$ Department of Biology, Biotechnical Faculty, University of Ljubljana,

Večna Pot 111, 1000 Ljubljana, Slovenia. ${ }^{2}$ Bavarian State Collection of Zoology, Münchhausenstr. 21, 81247 Munich, Germany. ${ }^{3}$ GeoBio Center LMU,

Richard-Wagner-Straße 10, 80333 Munich, Germany.

\section{Acknowledgements}

We thank Vreni Häussermann and Günter Försterra (Huinay Scientific Field Station) for carrying the yoke of the organization of all the "Huinay Fjordos" expeditions, and their great company on adventurous trips through the southern Chilean fjords. Special thanks go to the team of Huinay Scientific Field Station and the men of CAP Mineria Guarello for the great time and support on their island. We thank also to Andrea Weiss for preliminary work and to Elena Motivans for useful comments regarding language. An anonymous reviewer made useful suggestions regarding the paper including the idea for the update of the key of the group. This study was supported by grant of Sea Life Center Munich to Roland Melzer and also scholarship by Erasmus + mobility programme and Slovene Human Resources Development and Scholarship Fund to Vid Švara.

This paper is Publication No. 130 of the Huinay Scientific Field Station.

\section{Competing interests}

The authors declare that they have no competing interests.

Received: 8 August 2015 Accepted: 8 March 2016

Published online: 10 June 2016

\section{References}

1. Bamber R, El Nagar A, Arango C. PycnoBase: World Pycnogonida Database. http://www.marinespecies.org/pycnobase/. 12th of February 2016.

2. Bamber R, Thurston M. Deep water pycnogonids of the Cape Verde slope. J Mar Biol Assoc UK. 1993;73:837-61.

3. Child C. Antarctic and subAntarctic Pycnogonida: II. The family Austrodecidae. Biol Antarct Seas XXIII Antarct Res Ser. 1995;63:49-99.

4. Coleman CO. "Digital inking": how to make perfect line drawings on computers. Org Divers Evol. 2003;14:1-14. doi:10.1078/1439-6092-00081.

5. Coleman CO. Substituting time-consuming pencil drawings in arthropod taxonomy using stacks of digital photographs. Zootaxa. 2006;68:61-8.

6. Coleman CO. Drawing setae the digital way. Zoosyst Evol. 2009:85:30510. doi:10.1002/zoos.200900008.

7. Dietz L, Arango CP, Dömel JS, Halanych KM, Harder AM, Held C, Mahon AR, Mayer C, Melzer RR, Rouse GW, Weis A, Wilson NG, Leese F. Regional differentiation and extensive hybridization between mitochondrial clades of the Southern Ocean giant sea spider Colossendeis megalonyx. R Soc Open Sci. 2015;2(7):140424.

8. Häussermann V, Försterra G. Marine benthic fauna of Chilean Patagonia. Santiago: Nature in Focus; 2009.

9. Hedgpeth J. Reports of the Lund University Chile Expedition 1948-49, 40. Pycnogonida. Lunds Univ Arsskr NF Avd 2. 1961, p. 1-18

10. Stock J. The pycnogonid family Austrodecidae. Beaufortia. 1957;6:1-81.

11. Weis A, Melzer RR. How did sea spiders recolonize the Chilean fjords after glaciation? DNA barcoding of Pycnogonida, with remarks on phylogeography of Achelia assimilis (Haswell, 1885). Syst Biodivers. 2012;10:361-74.

12. Weis A, Meyer R, Dietz L, Dömel JS, Leese F, Melzer RR. Pallenopsis patagonica (Hoek, 1881) — a species complex revealed by morphology and DNA barcoding, with description of a new species of Pallenopsis Wilson, 1881. Zool J Linn Soc. 2014;170:110-31. doi:10.1111/zoj.12097.

\section{Authors' contributions}

VS did the microscopic analyses and digital inking, VS and RRM wrote the text. Both authors read and approved the final manuscript. 